\title{
Business and Information Systems Engineering Links Science with Entrepreneurship
}

In Germany, there is a deep trench between the scientific community and the practical people in enterprises. However, we need to link both in order to regain our position in the international market on innovation. The article takes research on business information systems as an example and illustrates how entrepreneurship could act as a catalyst for such a linking. It also describes the advantages for both science and economy. Finally, it proposes concrete suggestions for fostering innovation in research and industry so that both scientific researchers and industrial managers gain major advantages.

DOI 10.1007/s12599-008-0001-8

\section{The Author}

Prof. Dr. Dr. h.c. mult. August-Wilhelm Scheer

IDS Scheer AG

Professor of business and information systems engineering, Founder and supervisory board chairman of IDS Scheer AG and imc AG, President of BITKOM (German Association for Information Technology, Telecommunications and New Media)

Altenkesseler Str. 17

66115 Saarbrücken

Germany

ids@ids-scheer.com

Received: 2008-07-17

Accepted: 2008-08-28

Accepted after one revision

by Prof. Dr. Buhl.

This article is also available in German in print and via http://www. wirtschaftsinformatik.de: Scheer AW (2008) Wirtschaftsinformatik zwischen Wissenschaft und Unternehmertum. WIRTSCHAFTSINFORMATIK. doi 10.1007/s11576-008-0106-1

\section{Innovation needs entrepreneurship}

Business and Information Systems Engineering (BISE) is an application-oriented science. Its findings may have far-reaching effects if they find their way into products and concepts that influence the practical use of information systems within organizations.

If research results are to be translated into products, entrepreneurship will need to be involved. By entrepreneurship we understand the ability to implement visions from nothing, so to speak. This calls for entrepreneurship to be combined with attributes such as a willingness to assume risks as well as innovative capability (Schumpeter's “creative destroyer"). A good example of this is the story of Bill Gates, who dropped out of his course at Harvard to found what was to become the global giant Microsoft - from inside a garage. It is due to its practical relevance that BISE depends particularly on identifying entrepreneurial energy which will speed up the transfer of research results.

The strong influence of integrated information processing with the ERP approach has been clearly demonstrated by the overwhelming worldwide success of SAP software. The author of this article has likewise managed to make the ARIS concept for business process management - which was initially developed in the course of research - known throughout the world by founding the IDS Scheer AG, and by incorporating it in software products. Using ARIS as an example, we will now take a closer look at the process of transferring research results into products.

Between 1988 and 1992, the author developed the ARIS concept at the German Research Center (Institute for Information Systems (IWi) of Saarland University), and several prototypes were built to assist in the modeling process (Fig. 1) (e. g. Scheer 2002).

The prototypes focused on specific aspects (e. g. knowledge-based management of best practice cases, graphical design options) and used various technical platforms. No more than a dozen or so employees were involved in these research projects.

Around 1992 the research findings had reached a stage where the researchers considered this field completed. They were then ready to move on to new problems. The author, however, saw good opportunities for translating these results into software products with the aim of practical application. Several employees from the research team then joined IDS Scheer AG, which had been founded in 1984. It was here that they developed the product ARIS Toolset, based on the findings of their research. In technical terms it was developed from scratch using a uniform platform. The prototypes could not be applied in practice, as research prototypes do not satisfy product requirements. 


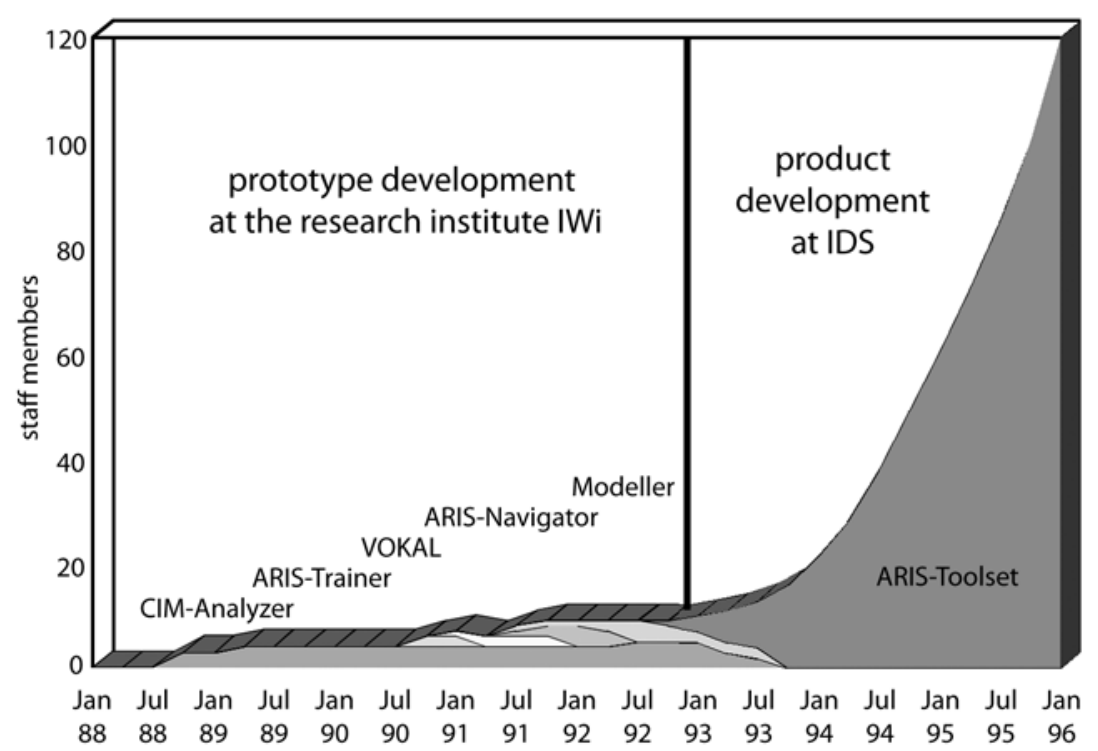

Fig. 1 The ARIS Toolset - from prototype to product development

Research prototypes:

- are unstable,

- do not cover all possible use cases, but merely represent theoretical solutions,

- do not offer convenient user guidance,

- are not extensively documented,

- have no marketing and distribution concept,

- have no defined strategy for further development,

- have no permanent development team on a long-term basis,

- show no preference for any standard commercial technical platforms, etc.

IDS Scheer AG therefore had to swiftly set up a group of 120 employees to develop ARIS. Hence, the capacity requirement was ten times greater than for prototype development. In the author's view this factor can be used as a general benchmark for the difference between the development of research prototypes and products in the field of BISE.

The example shows that in practice it is not possible to develop products at research institutes. It also clearly demonstrates that product development calls for high levels of investment, as well as a marked willingness to assume risk on the part of the entrepreneur. Hence, the transfer process is not possible without entrepreneurship.

However, entrepreneurship is also increasingly required for the transfer of BISE research results when it comes to acquiring the necessary resources for projects involving third-party funding. Conversely, companies from high-tech indus- tries depend on innovation. This means successful entrepreneurs have to work closely with the world of science if they are to determine the practicability of the latest research results. As a result, scientific research and entrepreneurship are no longer regarded as polar opposites, but as elements that complement one another.

We will therefore take a closer look in both directions: firstly, at the entrepreneurial requirements placed on researchers and secondly, at the research-related requirements placed on entrepreneurs. In addition, consideration will be given to the strengths, weakness and opportunities of the German IT research system.

Many points can also be transferred beyond the confines of BISE and into the high-tech sector as a whole, whereby the boundary between BISE and applicationoriented basic computer science is also addressed in some detail.

\section{Innovative IT products as prerequisite for future prosperity}

\subsection{Race for innovation}

Any short-term upturn in the economy cannot disguise the fact that German industry is suffering from structural problems. Given our well-known disadvantages as an industrial location, production capacity continues to shift to low-wage countries, thus reducing the number of jobs available in Germany.
Only products offering a high level of innovation are relatively unaffected by costs and remain competitive in countries with high wage levels. However, they too are at risk of moving to other countries, depending on their degree of maturity. Therefore, they need to be continually backed up by new process and product innovations. One thing becomes clear if we consider that exports account for forty percent of the German national economy: if Germany pulls out of the international innovation contest, it will pay for this with a dramatic decline in living standards. The race for innovation among the Western industrialized nations has thus begun. Who will ultimately be a winner or a loser in this race will depend on the extent to which each national economy manages to mobilize its reserves for innovation.

For Germany, IT and BISE have a particular significance. These disciplines do not only form an important growth market, but also act as a driving force behind the innovative ability of other industries. Nowadays IT plays a major role in the innovative further development in the fields of automotive, medical, and mechanical engineering. The competitiveness of all companies is ensured by modern, computer-aided organizational concepts from the field of BISE.

\subsection{IT creates opportunities}

Germany offers an outstanding research infrastructure in the field of IT and BISE: university research institutes, fundamental research performed by two IT institutes of the Max Planck Society in Saarbrücken, and applied research carried out by some 15 institutes of the Fraunhofer Society. This is backed up by the work of the German Research Foundation, the Federal Ministries (in particular the Ministry of Education and Research) and EU research programs, and also gains support from the Volkswagen Foundation, the Bertelsmann Foundation and the initiative Stifterverband der Deutschen Wirtschaft. Research activities in Germany therefore measure up very well in international comparison. What is lacking here, however, is a coherent strategy for coordinating the various research facilities, and for translating research results into successful products with market penetration.

The best known and widely quoted example here is development of the MP3 format at the Fraunhofer Insti- 
tute for Integrated Circuits in Erlangen. Although it failed to find an industrial taker in Germany, its hardware products, i. e. MP3 players, are mainly produced in Asia, with associated services, such as the iTunes Store, originating in the USA. Although these ideas were developed in Germany, the jobs created as a result are based abroad.

Germany is therefore beginning to rethink. The annual reports of the Max Planck Society and the Fraunhofer Society proudly mention the spin-offs from their institutes. In support of this, organizational and financial aid is also available. An increasing number of business incubator centers and science parks are springing up around the universities. The number of jobs created in relation to the employed funding of the institutions, however, is still too low. Innovation parks are often set up with good intentions, but are actually too small to keep pace with the large international melting pots of IT innovation such as Silicon Valley or Bangalore. In any case, the research landscape in Germany has not yet produced a large, globally successful company.

There is plenty of prominent international evidence that research can serve as an opening for attractive, future-oriented global IT companies, The USA has plenty of examples to offer, such as SUN, Google or CISCO, all of which started out as spinoffs from America's top university Stanford and have now become global organizations. Incidentally, when Google went public, Stanford University also received a windfall from its initial investment in the founding of the venture: figures ranging between several hundred million to over a billion dollars are being reported. This field has also given rise to recent successful company start-ups such as Facebook.

Besides such well-known examples from the USA, there is evidence in Europe that the countries with a thriving IT industry are those that create close links between research, education, and industrial transfer. Ireland, which today ranks as one of the most important locations in Europe for IT companies, is concentrating on training computer specialists at its universities in order to provide qualified staff for the IT companies setting up in the country. Finland has developed a clear-cut strategy for turning itself from a producer of rubber boots and car tires into the global market leader with Nokia in the cell phone sector. When developing its semiconduc- tor industry, South Korea worked out a systematic strategy for luring Korean researchers back from the research labs of the USA to their home country. By stepping up education and research, Malaysia has made major efforts to develop into a hightech nation from an agricultural country that was highly dependent on the production of tea and the London tea exchange. India and China are currently pursuing a successful route by systematically building up high-tech industries, while simultaneously speeding up the development of research and education facilities around industry itself.

While innovation in Silicon Valley is being driven forward by the opportunity of "getting rich" (with the classic American rags to riches dream of "pot washer to millionaire" giving way to the prospect of "garage owner to billionaire"), IT innovation in Asia is riding on a combination of state industrial policy and measures encouraging entrepreneurship.

Germany shies away from both approaches. Critical discussion constantly revolves around company profits and managers' salaries, which are without doubt insufficient to attract venture capitalists or encourage entrepreneurship. Active industrial policy is also seen as being problematic by key political parties in terms of regulatory policy. High levels of public funds are still being invested in IT research, but without any clear-cut objectives regarding economic benefit or rigorous monitoring of success. The high-tech strategy formulated by the Federal Ministry of Education and Research in 2007 therefore does not provide a basis for a comprehensive innovation strategy - despite a number of positive highlights.

Here it is more important to support the entire value chain, from fundamental and applied research to spin-off companies and their success in international markets. This requires linking research and entrepreneurial execution closely together. However, this depends on researchers and entrepreneurs not only being on the same wavelength, but also pursuing similar objectives and management methods during the collaboration process. Both have to be willing to learn from each other.

We have reasons to be confident: with funding becoming scarcer, entrepreneurial skills in terms of project acquisition are required when working in the research sector. At the same time there is a growing need for high-tech companies to understand the research landscape.

\section{Requirement profile for researchers and entrepreneurs}

We will now consider the entrepreneurial requirements placed on successful BISE researchers, and what knowledge of the research landscape is important for an IT entrepreneur to be successful.

\subsection{Entrepreneurial requirements placed on information systems researchers}

Teaching or motivating people to become entrepreneurs is no easy task. Departmental chairs of "Entrepreneurship" can help here, but it is not so much research into entrepreneurship that is involved here as discussion and analysis of practical success stories. Just as with bringing up children, the key is setting a "good example". Professors of BISE are also asked to do their bit here. If they act as role models for success by managing their chairs and institutes or own start-ups in a businesslike manner, they will motivate their students and employees to take entrepreneurial initiatives.

At the beginning of the last century there was a definite link between industry and science - even Albert Einstein patented a number of products. The technical universities were also founded during industrialization in order to train the engineers needed. However, after the Second World War science and industry rather drifted apart. This was largely prompted by the connection forced upon the two sectors during the Third Reich. This resulted in Germany's Basic Constitutional Law being formulated according to the principle of the "freedom of research and teaching". When researchers cooperate with industry, they are often accused of "betraying" this principle as the objectives and procedures involved in research projects financed by industry are too strongly influenced by the clients involved.

This has led many university professors to expect their research to be financed by basic state grants for their chairs. Merely attracting third-party funds through research applications submitted to state research aid organizations, such as the German Research Foundation or the Federal Ministry of Education and Research, is not regarded as part of the normal duty of 
a university professor, but more as additional effort on their part. In individual cases, university professors even believe that the mere submission of an application to such research organizations breaches "the freedom of research", as they are thereby subjecting themselves to a research program set up by a third party, or to an external assessment.

The financial constraints on states and the resulting constraints on the universities now increasingly mean that the resources provided by the basic grants are no longer sufficient to pursue the research topics of interest to them. At the same time, the ability to acquire third-party funding is also seen as a benchmark for assessing the performance of universities, faculties, specialist departments and chairs. The rankings, such as those as used by the Centre for Higher Education Development (CHE) or general-interest magazines, which were initially ridiculed by the universities, are now gaining real importance. The introduction of tuition fees is fueling competition between the universities. The Initiative for Excellence set up by the Federal Ministry of Education and Research is also encouraging competition.

This means that the ability to attract third-party funding is becoming increasingly important. If a university lecturer is to succeed in a resource-intensive subject such as BISE, he must also be a manager with an entrepreneurial approach. $\mathrm{He}$ must be capable of working out a strategy as well as a financing concept for his organization. He must maintain networks to other research institutions and possible partners in industry, and also cultivate connections with research aid organizations to ensure that he hears about new research projects in good time, so that he can prepare himself with the help of his research expertise at an early stage. Once his research project has been approved, he must be capable of carrying it out within the specified time, quality and cost requirements through professional project management. The acquisition of capable staff calls for skills in evaluating employees in the context of the "war for talents".

For the director of an institute to be successful, he must satisfy the same requirements as a successful manager in business. And this does not merely apply to the field of research and development. As the director of an institute has to attract thirdparty funds from "clients", the demands placed on him regarding the sales side are even greater than for an R\&D manager in industry - whether we like it or not.

\subsection{Research-related requirements placed on entrepreneurs}

As the post-war development described above prompted many lecturers and scientists engaged in fundamental research to retreat into an "ivory tower", industry was not greatly inclined to cooperate with the academic world on research projects. It was generally believed that researchers were either not interested in cooperating with industry, or that the end result would not be usable anyway. As waves of innovation are occurring so quickly, particularly in the IT industry, with fresh knowledge resulting in successful start-ups abroad, as shown by the above examples, a change has occurred.

Company founders from the universities who start up a business with an initial idea are then in need of further inspiration from their "old" research environment. This means they have to keep in touch with their former research institution. Established firms must be capable of evaluating and selecting the research partners of interest to them. It is evident that, for a successful career in industry, an academic background in BISE comes in very useful, while a good period of employment at a research institute (albeit not too lengthy) is also helpful here. In industry, an analytical mind and creativity are outstanding qualities for anyone looking for a successful career.

Examples of successful scientists who have moved on to succeed in business can also be found in Germany. Henning Kagermann, Professor of Theoretical Physics at the University of Brunswick, is today CEO and chairman of SAP AG, while Norbert Szyperski, doyen of BISE, subsequently became CEO of Mannesmann Kienzle and the driving force behind Mannesmann's switch to the telecommunications sector. The author could perhaps also be quoted as a further example, having founded IDS Scheer AG and imc AG, both successful IT companies. A scientific background therefore does not have to be an obstacle to a career in industry, but may well offer special opportunities, particularly in IT.

We can even go so far as to say that these days the best career opportunities in both research and industry are available to those who have proved themselves in both sectors, i. e. as a researcher and entre- preneur, thus measuring up to the high demands typical of both fields.

\section{Suggestions for accelerating structural change}

\subsection{Measures in the research sector}

In the research sector, the most important acceleration factor is a change in our system of values. At the same time, this is also the factor that is most difficult to bring about. It is no longer the scientist who produces the most footnotes and publishes insider knowledge in littleread, highly-specialized journals that is the ideal researcher - but the researcher who is able to follow through his or her ideas to the launch of a mature product. Dynamic research managers must therefore receive recognition at a scientific level. It is, however, no easy task to train such individuals and attract them to the world of research. People who can claim to have equally proved themselves both in research and management/business are thin on the ground and cannot therefore be attracted with the levels of pay offered by the public sector.

Such salaries might once have been sufficient while the managers of universities and large research facilities were appointed by a rotation system, as state-controlled further development of these organizations did not call for dynamic personalities. In the face of (global) competition for top-quality research managers, this pay structure is no longer adequate. The pay for an $R \& D$ director at a mediumsized company in the automotive component supply sector is around twice that of a university professor or the head of a Fraunhofer Institute. Only radical reform of the pay structure based on competition and performance can help here.

The recruitment process for research managers is another issue closely linked to this matter. The customary appointments process followed by the universities and extramural research institutes tends to be administrative in nature. When a vacancy is announced, it is already considered to be highly progressive if it does not just appear in German-language publications but also in foreign journals. The long list of demands placed on applicants is often impressive, but does not automatically attract suitable candidates. On the 
contrary, if these requirements are too wide-ranging, it is questionable whether suitable candidates would ever need to respond to such an advertisement. Given the pay levels on offer, most people would not be interested in leaving industry.

The recruitment process must therefore be improved through the involvement of HR consultants. They selectively approach candidates who have perhaps never imagined working for a public research facility. At the same time, consultants can point out possible exceptions to the rules in relation to pay which cannot be included when announcing vacancies. Lastly, assessment and shortlisting by an experienced HR consultant can prevent unconventional candidates from being ruled out at an early stage.

These requirements are not satisfied by the procedures currently used to advertise for research managers. The appointments boards are relatively large, subject to the influence of various interest groups and frequently lacking in the relevant specialist skills. Whether other candidates should and can be headhunted depends on the quality of the chairman of the appointments committee. Professional assessment and detailed HR discussions do not generally take place. In particular, more than one interview is rarely held. A flexible remuneration structure and an efficient appointments process are therefore major prerequisites if research institutions are to be organized in a more businesslike and effective manner.

Additional acceleration factors for innovative research and transfer processes are already being pursued with varying degrees of urgency. These include the requirement of channeling public research aid into cooperative projects involving collaboration between researchers from public institutions and industrial partners. Here it is also necessary to recognize the role played by the institute as the source of ideas and the institution assisting the implementation of the idea. Both institute and researchers must be rewarded for the economic success of their ideas.

Researchers whose ideas have already been successfully translated into product innovations should receive preferential treatment when applying for new research funding on the basis of their proven success.

\section{Abstract \\ August-Wilhelm Scheer \\ Business and Information Systems Engineering Links Science with Entrepreneurship}

One of the major success indicators for applied research sciences is the rate of transfer from research into practice. Only if concrete and economically successful products are derived from research results, such sciences can induce an impact. However, this process of innovation mandatorily needs entrepreneurship. Within the domain of business information systems, the two German enterprises SAP AG and IDS Scheer AG demonstrate that linking research and innovation is the key to lasting success on the information technology markets.

German industry has significant disadvantages concerning the cost of human resources. Therefore it can be only successful with products that incorporate a high degree of innovation and that are consequently highly priced. But the invention of such products needs scientific research as a source of inspiration. Germany has a highly developed infrastructure of research facilities and organizations. However, they need to be better coordinated and aligned with business needs. Vice versa, enterprises need to actively approach the scientific community in order to clearly formulate their demand.

Such a strategy requires changes on all sides. To achieve a change in the domain of science, it is necessary to change the profile of leading researchers, such as full professors. They should incorporate attributes of an entrepreneur and be profiled more as a research manager who tries to anticipate future needs and to develop their unit in terms of research subjects as well as personnel and financial resources. Consequently, the process of application, selection and review of leading researchers should be more oriented on processes that are common in enterprises. E. g. external head-hunters can be involved in the searching and assessing process in order to obtain the best qualified person for the research vacancy. Also enterprises need to change their attitude towards scientific research. In order to foster this process, executives could be invited to advisory and supervisory boards of research organisations. Furthermore, these executives must be proactively informed about the research activities and results in order to attract their interest and to show potentials for a transfer into products. There is still a long way to go in the hunt for innovation leadership and all these suggestions can only be a starting point.

Keywords: Business information systems, Entrepreneurship, Research transfer, Product innovation, Innovation challen 


\subsection{Suggestions for industry}

The willingness of companies to take part in publically funded research projects can be encouraged by eliminating bureaucratic obstacles. Applications for research funding, for example those submitted to the EU, are associated with excessive red tape where small and medium enterprises are concerned. It is therefore necessary to simplify the application procedure for such firms. Above all, companies that have already successfully taken part in research projects should be given preference when it comes to new applications.

To make the research system more transparent for industry, as many representatives as possible from business should be appointed to the supervisory bodies of institutes, universities and extramural research facilities. Personal contact remains the best way of counter- acting prejudice and identifying areas of common interest. It is, however, not easy to secure the commitment of staff with outstanding practical skills. The university boards set up with such enthusiasm show that the meeting-attendance level of busy managers from industry could be better, as could their participation in critical decision-making problems. It is therefore important for the meetings of such bodies to feature the information that is of great interest and benefit to representatives from industry, and to cut down on the administrative issues and technicalities relating to the institute's organization.

The offer of research institutions to admit industrial partners to their information events and training seminars, and to also allow them to use their technical facilities, is an effective option for encouraging an interest in closer cooperation.
The acceleration factors described above for research and industry are, of course, not exhaustive. They do, however, provide a clear indication that there is major potential for improving cooperation between research and industry to ensure a more efficient innovation cycle for business and information systems engineering.

\section{Literatur}

Scheer AW (2002) ARIS. Vom Geschäftsprozess zum Anwendungssystem, 4th edn. Springer, Heidelberg 